\title{
Diversidade e uso de plantas do Cerrado na comunidade São Miguel, Várzea Grande, MT, Brasil
}

\author{
Diversity and use of Cerrado plants in the community São Miguel, \\ Várzea Grande, MT, Brazil \\ Diversidad y uso de plantas del Cerrado en la comunidad San Miguel, \\ Várzea Grande, MT, Brasil \\ Jenefer Soares dos Santos Mamede ${ }^{1}$ \\ Maria Corette Pasa ${ }^{1}$
}

Recebido em 27/06/2018; revisado e aprovado em 20/12/2018; aceito em 27/01/2019

DOI: http://dx.doi.org/10.20435/inter.v20i4.2064

\begin{abstract}
Resumo: O presente estudo teve como objetivo identificar as espécies de plantas nativas mais importantes para essa comunidade, analisar a diversidade de uso e a diversidade de plantas, e relacionar o valor de uso com a disponibilidade das plantas no ambiente. Adotaram-se as técnicas de entrevistas semiestruturadas. No levantamento etnobotânico, foram catalogadas 67 espécies distribuídas em 30 famílias botânicas. As espécies mais importantes para a comunidade, conforme o valor de uso, foram cumbaru, angico e aroeira. Estudos com plantas nativas podem gerar alternativas eficazes que diminuam o impacto da coleta sobre as populações naturais.
\end{abstract}

Palavras-chave: etnobotânica; conhecimento popular; valor de uso.

Abstrat: The present study aimed to identify the most important native plant species for this community, to analyze the diversity of use and the diversity of plants, and to relate the value of use with the availability of plants in the environment. The techniques of semi-structured interviews were adopted. In the ethnobotanical survey were cataloged 67 species distributed in 30 botanical families. The most important species for the community, according to the use value were cumbaru, angico and aroeira. Studies with native plants can generate effective alternatives that diminish the impact of the collection on the natural populations.

Keywords: ethnobotany; popular knowledge; uso.rais value.

Resumen: El presente estudio tuvo como objetivo identificar las especies de plantas nativas más importantes para esa comunidad, analizar la diversidad de uso y la diversidad de plantas, y relacionar el valor de uso con la disponibilidad de las plantas en el ambiente. Se adoptaron las técnicas de entrevistas semiestructuradas. En el levantamiento etnobotánico se catalogaron 67 especies distribuidas en 30 familias botánicas. Las especies más importantes para la comunidad, según el valor de uso, fueron cumbaru, angio y aroeira. Estudios con plantas nativas pueden generar alternativas eficaces que disminuyan el impacto de la recolección sobre las poblaciones naturales.

Palabras clave: etnobotánica; el conocimiento popular; el valor de uso.

\section{INTRODUÇÃO}

O Cerrado brasileiro é reconhecido como a savana mais rica do mundo, ocupa $21 \%$ do território nacional, abrigando 11.627 espécies de plantas nativas já catalogadas com extrema abundância de espécies endêmicas (BRASIL, s.d.) e possui os principais aquíferos subterrâneos, o que o torna imprescindível para a segurança hídrica de milhões de pessoas (MENDONÇA; PELÁ, 2011). Aproximadamente a metade dos 2 milhões de $\mathrm{km}^{2}$ originais do Cerrado foram substituídos por pastagens plantadas, culturas anuais e outros tipos de uso (KLINK; MACHADO, 2005). A perda da diversidade está transformando esse bioma em um hotspots, apesar de o Cerrado mato-grossense contar com múltiplas opções de aproveitamento de seus recursos vegetais e as

\footnotetext{
${ }^{1}$ Universidade Federal de Mato Grosso (UFMT), Cuiabá, Mato Grosso, Brasil.
} 
populações locais serem os primeiros detentores do conhecimento botânico (GUARIM-NETO, 2001).

Nessa perspectiva, caracterizar essa relação é essencial uma vez que a população local se diferencia pelo conhecimento que possui dos recursos naturais, pelo uso sustentável de tais recursos e por ocuparem o mesmo território por gerações. Novas informações são adicionadas ao conhecimento regional gradativamente e está passível às mudanças em resposta a inovações, experiências e pressões ambientais externas. O conhecimento armazenado apenas na memória dos povos que vivem do Cerrado acaba se perdendo sem o devido registro, o que acarreta uma perda enorme de informação. Esse panorama é o que tem motivado alguns pesquisadores a resgatar esse conhecimento através da etnobotânica no Estado de Mato Grosso, como por exemplo: Guarim-Neto (2001), Amorozo (2002), Pasa, Soares e Guarim-Neto (2005), Souza (2007), Valentini et al. (2008), Sólon, Brandão e Siqueira (2009), Carniello et al. (2010), Pasa (2011a; 2011b), Mamede et al. (2015). Contudo as investigações etnobotânicas na região do Cerrado mato-grossense são ainda escassas, especialmente quando comparada a sua diversidade natural e cultural e as áreas que estas ocupam (MOREIRA; GUARIM-NETO, 2009).

A procedência do saber popular está na observação constante e metódica dos fenômenos e das características da natureza e na experimentação desses recursos, o que explica a importância que as etnocategorias de usos das plantas assumem nos resultados das investigações etnobotânicas de uma região ou mesmo de uma sociedade (ALBUQUERQUE; ANDRADE, 2002). A etnobotânica surge como o campo interdisciplinar que envolve o estudo e a explicação do conhecimento que o ser humano possui da significação cultural, manejo e usos tradicionais dos elementos da flora (CABALLERO, 1979). Para Amorozo (2002), engloba a maneira como um grupo social classifica as plantas e as utilizam. Logo, podemos ponderar o etnoconhecimento como uma ferramenta metodológica que implica a abordagem do conhecimento cultural e regional e que conduz à informação, resgatando o vínculo entre o saber popular e o científico.

Nesse cenário, este estudo não tem um caráter definitivo nem possui a ambição de exaurir o assunto, contudo a de mostrar a utilização da etnobotânica e do etnoconhecimento em uma comunidade local do Estado de Mato Grosso, com foco no saber popular sobre as plantas do bioma Cerrado. O presente estudo teve como objetivo identificar as espécies de plantas nativas mais importantes para essa comunidade, analisar a diversidade de uso e a diversidade de plantas e ainda relacionar o valor de uso com a disponibilidade das plantas no ambiente. As questões norteadoras deste trabalho foram: Existe uma diversidade de plantas utilizadas pela comunidade? Que espécies são mais importantes? Quais as finalidades de uso das espécies?

\section{METODOLOGIA}

\section{1 Área de estudo}

O presente estudo foi realizado na Comunidade São Miguel, zona rural do município de

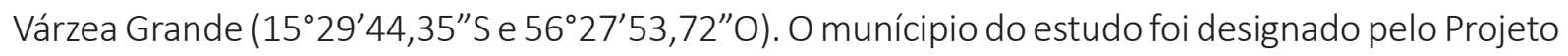
Radambrasil (BRASIL, 1982) como uma região da Depressão Cuiabana, com extensão territorial de $949,53 \mathrm{~km}^{2}$ e encontra-se localizado no Estado de Mato Grosso. O clima da região é caracterizado como tropical semiúmido (Aw), com precipitação pluviométrica anual de $1.350 \mathrm{~mm}$, a temperatura média anual é de 26 ○ $\mathrm{C}$ e a umidade relativa do ar com a média anual em torno de $74 \%$ (VERTRAG, 2007). Solo predominantemente de argila avermelhada, principalmente na faixa 
marginal do Rio Cuiabá (ROMANCINI; MOURA, 2012). Essa comunidade compõe um dos mais expressivos corpos florestais do Estado de Mato Grosso, caracterizado por densa cobertura da fitofisionomia savana arborizada, bioma Cerrado, sendo recortado pelo rio Ribeirão Espinheiro.

O acesso à comunidade se dá através da BR 163, partindo de Várzea Grande em direção à cidade de Jangada. Há meio de transporte coletivo que dá acesso aos moradores da comunidade para aos municípios de Várzea Grande e Cuiabá. A região de estudo está distante cerca de 44 km do centro de Várzea Grande e 62 km de Cuiabá. O tempo gasto para chegar à comunidade é de, aproximadamente, uma hora e meia de carro e três de ônibus. A Escola Municipal intitulada como Advogado Osmar Milan Capile funciona em três turnos: matutino, vespertino e noturno, com ensino regular de educação infantil e ensino fundamental, além da educação de jovens e adultos (EJA). Existe transporte escolar para os moradores. Os recursos médicos são oferecidos pelo Posto de Saúde Familiar (PSF), com atendimento de sistema de consulta agendada em uma sala disponibilizada na escola local. Em casos de urgência e emergência, as pessoas recorrem aos hospitais ou postos de saúde do município e das cidades vizinhas. Observou-se que a comunidade não é atendida pelos serviços de coleta de lixo nem de esgoto. A comunidade São Miguel tem como atividade de subsistência a agricultura em pequenas áreas de cultivares como mandioca, banana, hortaliças e árvores frutíferas. As produções são para consumo próprio ou comercializado na vila local.

\subsection{Proposta metodológica}

Inicialmente, realizou-se uma visita para o reconhecimento da área de estudo, em que se aplicou um pré-teste com os moradores para escolher e avaliar as técnicas a serem utilizadas junto à população local (PASA et al., 2013). Foram entrevistados 46 informantes aleatoriamente, sendo 29 mulheres e 17 homens. As entrevistas foram realizadas nas residências dos próprios entrevistados, com uma pessoa da família que estivesse no local, maior de idade e que detivesse informações a respeito daquele grupo familiar, independente do sexo.

A entrevista aconteceu entre o pesquisador e o morador apenas, para que os dados não fossem influenciados por terceiros. Conforme Albuquerque, Lucena e Alencar (2010), a presença de uma terceira pessoa durante a entrevista pode adulterar as respostas dos entrevistados. Foram esclarecidos para cada entrevistado os objetivos do estudo, e os moradores que aceitaram participar da pesquisa assinaram o Termo de Consentimento Livre e Esclarecido autorizando a realização da pesquisa. Esse termo permite que a pessoa que está sendo convidada a participar da pesquisa entenda os procedimentos, riscos, desconfortos, benefícios e direitos envolvidos.

Para a coleta das informações, foram utilizadas entrevistas semiestruturadas, caminhada com os entrevistados dentro da propriedade e/ou em seus arredores para observação da vegetação, diário de campo, gravação de áudio e fotografias. As plantas citadas pelos informantes foram identificadas no local da entrevista de acordo com o conhecimento do autor. As coletas de amostras vegetais das espécies (em fases reprodutiva e vegetativa) foram realizadas durante as caminhadas e posteriormente realizou-se a montagem das exsicatas. As exsicatas do material botânico foram identificadas por especialistas do Herbário Central da Universidade Federal de Mato Grosso (UFMT), onde se encontram catalogadas e depositadas. A grafia dos binômios científicos e dos autores foi conferida em revisões taxonômicas recentes e utilizando a base de dados do Missouri Botanical Garden e no Flora do Brasil 2020. 


\subsection{Análise dos dados}

As etnocategorias de uso foram representadas de forma literal, exatamente como foram citadas pelos entrevistados: alimentar (AI), artesanal (Ar), inseticida (In), madeireiro (Ma), medicinal (Me) e tempero (Te). Lembrando que uma espécie pode ser agrupada em mais de uma categoria de uso, fato recorrente observado nas citações dos entrevistados. Para cada espécie foi calculado o Valor de Uso (UVs), entrevistando-se uma única vez cada informante, conforme referido por Phillips e Gentry (1993):

a) O valor de uso de cada espécie (sp) por informante (i), dado como:

$$
\text { VUspi }=\frac{\Sigma \text { Uspi }}{\text { nspi }}
$$

Onde, Uspi é o número de usos mencionados por informante i por espécie sp em cada evento, e nspi é o número de eventos com o informante i por espécie sp

b) O valor de uso global de cada espécie (VUsp), dado como:

$$
\text { VUsp }=\frac{\Sigma \text { VUspi }}{\text { ns }}
$$

Onde, ns é o número de informantes entrevistados por espécie.

\section{RESULTADOS E DISCUSSÃO}

Nesta pesquisa, foram registradas 67 etnoespécies, sendo estas distribuídas em 30 famílias botânicas e 60 gêneros. As famílias mais representativas foram Fabaceae (12 espécies), e Rubiaceae (seis espécies). Estas também foram relatadas como as mais significativas em outros estudos etnobotânicos em diversas regiões do país, como Cunha e Bortolloto (2011), Daher et al. (2012), Zucchi et al. (2013) e Paes e Pasa (2014), de fato devido às suas propriedades antibacteriana, antifúngica e anti-inflamatória (MONTEIRO et al., 2005).

A maior riqueza de etnoespécies foi encontrada na categoria medicinal (Figura 1). As plantas usadas na medicina caseira mais citadas foram: aroeira (26), cumbaru (24), jatobá-do-cerrado (19), quina (16) e angico (13), sendo que a aroeira e o jatobá-do-cerrado são etnoespécies comumente utilizados para fins madeireiros. O uso dessas espécies no tratamento de enfermidades, explica-se pela alta concentração de fenóis e taninos presentes na casca e folha da aroeira (QUEIROZ; MORAIS; NASCIMENTO, 2002; MONTEIRO et al., 2005), e a presença de polifenóis e taninos na casca do jatobá-do-cerrado (BEZERRA, 2013). 
Figura 1 - Categorias de usos das espécies catalogadas no levantamento etnobotânico na Comunidade São Miguel

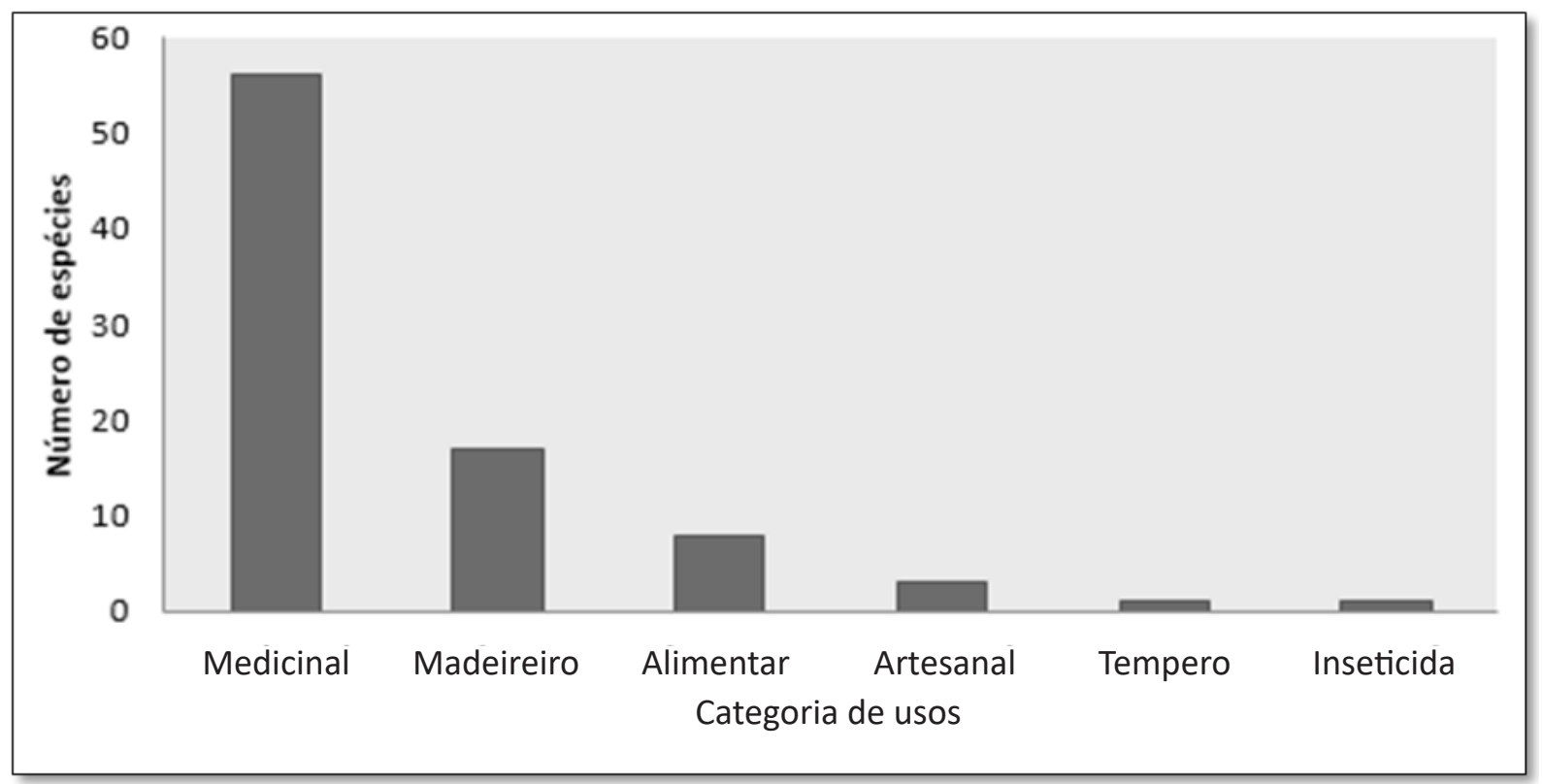

Fonte: Acervo autoras.

Além das etnoespécies supramencionadas para aproveitamento madeireiro, foram referidas também o guatambu, o angico e o cedro. Na figura 2, são apresentadas algumas formas de uso das madeiras encontradas nas casas dos entrevistados. Segundo estes, a lenha utilizada no preparo da comida é proveniente de ramos caídos no solo, não existindo preferência por uma única espécie. Conforme estudos realizados pela Embrapa (s.d.), o Cerrado pode ter em torno de 6.500 espécies da flora lenhosa pouco conhecida do ponto de vista da tecnologia da madeira (processos de transformação física e química da madeira). Poucos estudos são realizados sobre as madeiras encontradas no Cerrado, especialmente o modo como as comunidades utilizam esses recursos; como diferenciam a madeira para o tipo de finalidade desejada; a época da retirada dessas árvores, e se realizam o reflorestamento para repor na natureza as árvores retiradas e garantir recursos no futuro.

Figura 2- Formas da utilização da madeira na Comunidade São Miguel

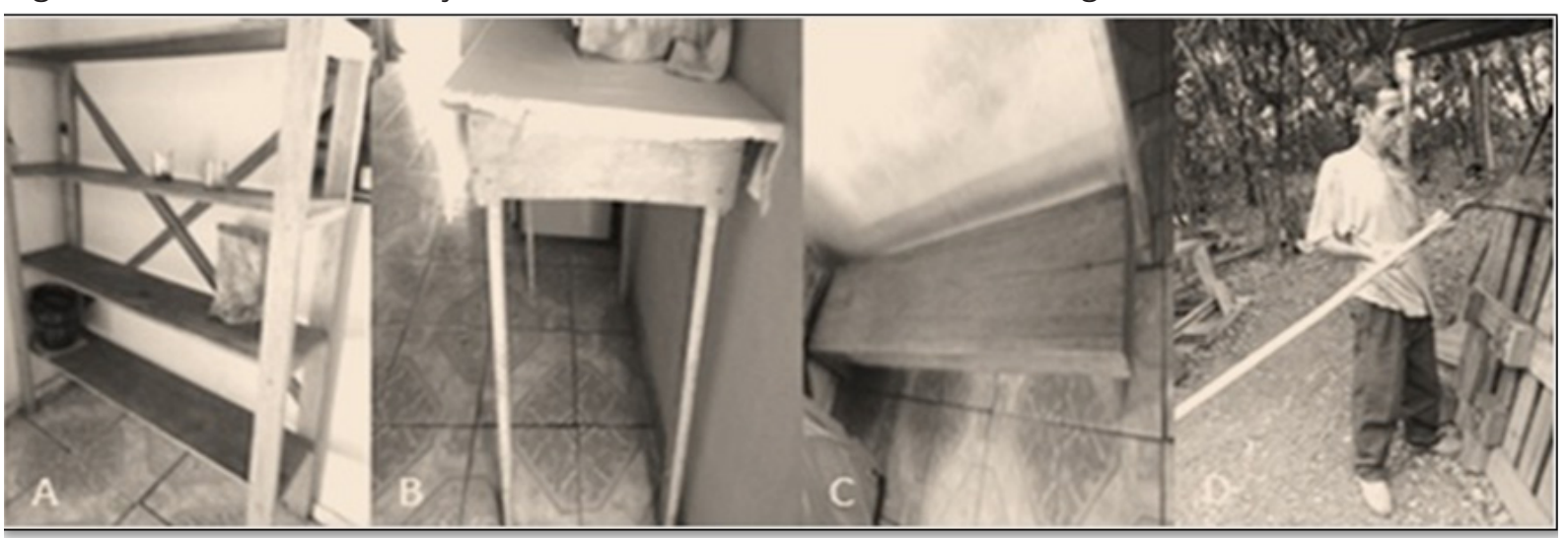

A: Prateleira, B: Mesa, C: Banco; D: Cabo de ferramenta.

Fonte: Acervo autoras. 
Convém ressaltar que a categoria de uso de uma espécie vegetal pode ser cumulativa, uma espécie pode ser utilizada para a alimentação e, ao mesmo tempo, ser empregada na cura de enfermidades. Neste estudo, as espécies que se destacaram por apresentar usos múltiplos foram: cumbaru, mangava-mansa, bocaiuva e ipê-roxo. As várias formas de usos de uma espécie têm a vantagem de proporcionar uma renda extra para as famílias e, por outro lado, podem acarretar a extinção das mesmas.

As plantas levantadas estão distribuídas em cinco tipos de hábito: arbóreo (64\%), arbustivo (24\%), subarbustivo (9\%), palmeira e trepadeira (1,5\%). Nota-se que o hábito arbóreo foi dominante, o que evidencia a importância desse componente no ecossistema florestal para o extrativismo nessa região. Os recursos vegetais mais encontrados foram, em ordem de importância, folha $(45,2 \%)$, caule $(20,2 \%)$, fruto $(13,1 \%)$, casca $(12 \%)$, semente $(8,3 \%)$ e exsudato $(1,2 \%)$. Os exsudatos correspondem à resina, seiva, látex e óleo-resina. O uso de recursos vegetais que prejudicam a sobrevivência da planta, como é o caso da casca, é capaz de impedir a conservação das espécies exploradas. O fato de as cascas, obtidas principalmente de espécies arbóreas, serem as partes vegetativas mais habitualmente aproveitadas pela comunidade, reporta a preocupações sobre a conservação das espécies exploradas, sobretudo aquelas classificadas como ameaçadas de extinção, como cedro, ipê-roxo e pau-rosa. Outra opção que vem sendo recomendada é a substituição por outras partes da planta cujo uso ofereça menor risco, como as folhas. Porém é preciso ponderar que isso abrange comprovações científicas que carecem de investimentos em pesquisas para cada espécie (ZSCHOCKE et al., 2000).

Tabela 1- Espécies do Cerrado utilizadas na Comunidade São Miguel.

\begin{tabular}{|c|c|c|c|c|c|}
\hline Nome científico/família & $\begin{array}{l}\text { Nome } \\
\text { popular }\end{array}$ & Usos & $\begin{array}{l}\text { Parte } \\
\text { usada }\end{array}$ & Hábito & VUsp \\
\hline $\begin{array}{l}\text { Dipteryx alata Vogel } \\
\text { Fabaceae }\end{array}$ & Cumbaru & Al, Ma, Me & $\begin{array}{l}\text { Fruto } \\
\text { Caule }\end{array}$ & AV & 2,18 \\
\hline $\begin{array}{l}\text { Anadenanthera colubrina (Vell.) Brenan } \\
\text { Fabaceae }\end{array}$ & Angico & Ar, Ma, Me & $\begin{array}{c}\text { Sementes } \\
\text { Caule }\end{array}$ & AV & 1,86 \\
\hline $\begin{array}{l}\text { Myracrodruon urundeuva Allemão } \\
\text { Anacardiaceae }\end{array}$ & Aroeira & Me, Ma & $\begin{array}{l}\text { Caule } \\
\text { Casca } \\
\end{array}$ & AV & 1,86 \\
\hline $\begin{array}{l}\text { Handroanthus heptaphyllus (Vell.) } \\
\text { Mattos } \\
\text { Bignoniaceae }\end{array}$ & Ipê roxo & Ma, Me & $\begin{array}{l}\text { Caule } \\
\text { Folha }\end{array}$ & AV & 1,67 \\
\hline $\begin{array}{l}\text { Hancornia speciosa Gomes } \\
\text { Apocynaceae }\end{array}$ & $\begin{array}{l}\text { Mangava } \\
\text { mansa }\end{array}$ & Al, Me & $\begin{array}{l}\text { Fruto } \\
\text { Casca }\end{array}$ & AV & 1,50 \\
\hline $\begin{array}{l}\text { Diospyros lasiocalyx (Mart.) B.Walln. } \\
\text { Ebenaceae }\end{array}$ & Olho-de-boi & Ar, Me & Semente & $A B$ & 1,50 \\
\hline Guazuma ulmifolia Lam. Malvaceae & Chico-magro & Ma, Me & Caule & AV & 1,50 \\
\hline Copaifera langsdorffii Desf. Fabaceae & Pau-de-óleo & Ma, Me & $\begin{array}{c}\text { Caule } \\
\text { Exsudato }\end{array}$ & AV & 1,50 \\
\hline $\begin{array}{l}\text { Tabebuia aurea (Silva Manso) Benth. \& } \\
\text { Hook. f. ex S. Moore Bignoniaceae }\end{array}$ & Paratudo & Ma, Me & $\begin{array}{l}\text { Caule } \\
\text { Folha }\end{array}$ & AV & 1,50 \\
\hline Chiococca alba (L.) Hitchc. Rubiaceae & Cainca & Me & Folha & $A B$ & 1,50 \\
\hline Ricinus communis L. Euphorbiaceae & Mamona & In, Me & Semente & $A B$ & 1,33 \\
\hline $\begin{array}{l}\text { Terminalia argentea Mart. } \\
\text { Combretaceae }\end{array}$ & $\begin{array}{l}\text { Capitão do } \\
\text { campo }\end{array}$ & Me & Casca & AV & 1,33 \\
\hline
\end{tabular}




\begin{tabular}{|c|c|c|c|c|c|}
\hline Nome científico/família & $\begin{array}{l}\text { Nome } \\
\text { popular }\end{array}$ & Usos & $\begin{array}{l}\text { Parte } \\
\text { usada }\end{array}$ & Hábito & VUsp \\
\hline $\begin{array}{l}\text { Acrocomia aculeata (Jacq.) Lodd. ex. } \\
\text { Mart. } \\
\text { Arecaceae }\end{array}$ & Bocaiúva & $\mathrm{Al}, \mathrm{Me}$ & Fruto & PAL & 1,33 \\
\hline $\begin{array}{l}\text { Genipa americana } \mathrm{L} . \\
\text { Rubiaceae }\end{array}$ & Jenipapo & Al, Me & $\begin{array}{l}\text { Fruto } \\
\text { Folha }\end{array}$ & AV & 1,33 \\
\hline $\begin{array}{l}\text { Bixa orellana } \mathrm{L} . \\
\text { Bixaceae }\end{array}$ & Urucum & $\mathrm{Te}, \mathrm{Me}$ & Semente & $A B$ & 1,30 \\
\hline $\begin{array}{l}\text { Stryphnodendron adstringens (Mart.) } \\
\text { Coville } \\
\text { Fabaceae }\end{array}$ & Barbatimão & Me & Casca & AV & 1,17 \\
\hline $\begin{array}{l}\text { Hymenaea courbaril L. } \\
\text { Fabaceae }\end{array}$ & $\begin{array}{l}\text { Jatobá-do- } \\
\text { cerrado }\end{array}$ & $\mathrm{Ar}, \mathrm{Ma}, \mathrm{Me}$ & $\begin{array}{l}\text { Caule } \\
\text { Semente }\end{array}$ & AV & 1,12 \\
\hline Annona crassiflora Mart. Annonaceae & Araticum & Al & Fruto & AV & 1,00 \\
\hline $\begin{array}{l}\text { Artocarpus altilis (Parkinson) Fosberg } \\
\text { Moraceae }\end{array}$ & Fruta pão & Al & Fruto & AV & 1,00 \\
\hline $\begin{array}{l}\text { Annona reticulata } \mathrm{L} . \\
\text { Annonaceae }\end{array}$ & $\begin{array}{l}\text { Fruta-do- } \\
\text { conde }\end{array}$ & Al & Fruto & AV & 1,00 \\
\hline $\begin{array}{l}\text { Inga heterophylla Willd. } \\
\text { Fabaceae }\end{array}$ & Ingá-do-mato & Al, Me & Fruto & AV & 1,00 \\
\hline $\begin{array}{l}\text { Callisthene fasciculata Mart. } \\
\text { Vochysiaceae }\end{array}$ & $\begin{array}{l}\text { Carvão- } \\
\text { branco }\end{array}$ & $\mathrm{Ma}$ & Caule & AV & 1,00 \\
\hline $\begin{array}{l}\text { Diptychandra aurantiaca Tul. } \\
\text { Fabaceae }\end{array}$ & $\begin{array}{c}\text { Carvão } \\
\text { vermelho }\end{array}$ & $\mathrm{Ma}$ & Caule & AV & 1,00 \\
\hline Cedrela fissilis Vell.- Meliaceae & Cedro & $\mathrm{Ma}$ & Caule & AV & 1,00 \\
\hline $\begin{array}{l}\text { Cordia trichotoma (Vell.) Arráb. ex } \\
\text { Steud. } \\
\text { Boraginaceae }\end{array}$ & Louro pardo & Ma & Caule & AV & 1,00 \\
\hline $\begin{array}{l}\text { Magonia pubescens A. St.-Hil. } \\
\text { Sapindaceae }\end{array}$ & Timbó & $\mathrm{Ma}$ & Caule & AV & 1,00 \\
\hline $\begin{array}{l}\text { Plathymenia reticulata Benth. } \\
\text { Mimosaceae }\end{array}$ & Vinhático & Ma & Caule & AV & 1,00 \\
\hline $\begin{array}{l}\text { Aspidosperma polyneuron Müll. Arg. } \\
\text { Apocynaceae }\end{array}$ & Guatambu & Ma, Me & $\begin{array}{l}\text { Caule } \\
\text { Casca }\end{array}$ & AV & 1,00 \\
\hline $\begin{array}{l}\text { Vatairea macrocarpa (Benth.) Ducke } \\
\text { Fabaceae }\end{array}$ & $\begin{array}{l}\text { Angelim } \\
\text { margoso }\end{array}$ & Ma, Me & $\begin{array}{l}\text { Caule } \\
\text { Casca }\end{array}$ & AV & 1,00 \\
\hline $\begin{array}{l}\text { Aspidosperma tomentosum Mart. } \\
\text { Apocynaceae }\end{array}$ & Peroba & $\mathrm{Ma}$ & Caule & AV & 1,00 \\
\hline $\begin{array}{l}\text { Brosimum gaudichaudii Trécul } \\
\text { Moraceae }\end{array}$ & Algodãozinho & $\mathrm{Me}$ & Folha & $A B$ & 1,00 \\
\hline Cordia insigns Cham. Boraginaceae & $\begin{array}{l}\text { Calção de } \\
\text { velho }\end{array}$ & $\mathrm{Me}$ & $\begin{array}{l}\text { Casca } \\
\text { Folha }\end{array}$ & $A B$ & 1,00 \\
\hline $\begin{array}{l}\text { Vernonanthura ferruginea (Less.) } \\
\text { H.Rob. } \\
\text { Asteraceae }\end{array}$ & Assa-peixe & Me & Folha & $A B$ & 1,00 \\
\hline $\begin{array}{l}\text { Homalolepis ferruginea (A.St.-Hil.) } \\
\text { Devecchi \& Pirani Simaroubaceae }\end{array}$ & Calunga & $\mathrm{Me}$ & Folha & AV & 1,00 \\
\hline $\begin{array}{l}\text { Rudgea viburnoides (Cham.) Benth. } \\
\text { Rubiaceae }\end{array}$ & $\begin{array}{c}\text { Congonha-de- } \\
\text { bugre }\end{array}$ & $\mathrm{Me}$ & Folha & $A B$ & 1,00 \\
\hline
\end{tabular}




\begin{tabular}{|c|c|c|c|c|c|}
\hline Nome científico/família & $\begin{array}{l}\text { Nome } \\
\text { popular }\end{array}$ & Usos & $\begin{array}{l}\text { Parte } \\
\text { usada }\end{array}$ & Hábito & VUsp \\
\hline Palicourea rigida Kunth- Rubiaceae & $\begin{array}{l}\text { Douradão do } \\
\text { campo }\end{array}$ & Me & Folha & SA. & 1,00 \\
\hline $\begin{array}{l}\text { Palicourea coriacea (Cham) K. Schum. } \\
\text { Rubiaceae }\end{array}$ & Douradinha & Me & Folha & $A B$ & 1,00 \\
\hline $\begin{array}{l}\text { Cecropia pachystachya Trécul- } \\
\text { Urticaceae }\end{array}$ & Embaúba & Me & $\begin{array}{l}\text { Folha } \\
\text { Fruto }\end{array}$ & AV & 1,00 \\
\hline $\begin{array}{l}\text { Celtis iguanaea (Jacq.) Sarg.- } \\
\text { Cannabaceae }\end{array}$ & $\begin{array}{l}\text { Esporão-de- } \\
\text { galo }\end{array}$ & Me & Folha & $A B$ & 1,00 \\
\hline Senna occidentalis (L.) Link- Fabaceae & Fedegoso & Me & $\begin{array}{c}\text { Folha } \\
\text { Semente }\end{array}$ & SA. & 1,00 \\
\hline Piper tuberculatum Jacq.-Piperaceae & Jaborandi & Me & Folha & $A B$ & 1,00 \\
\hline $\begin{array}{l}\text { Libidibia ferrea (Mart. ex Tul.) } \\
\text { L.P.Queiroz } \\
\text { Fabaceae }\end{array}$ & Jucá & Me & $\begin{array}{l}\text { Folha } \\
\text { Semente }\end{array}$ & AV & 1,00 \\
\hline Curatella americana L.- Dilleniaceae & Lixeira & Me & Folha & $A B$ & 1,00 \\
\hline Davilla elliptica A. St.-Hil- Dilleniaceae & Lixinha & Me & Folha & $A B$ & 1,00 \\
\hline $\begin{array}{l}\text { Zanthoxylum rhoifolium Lam. } \\
\text {-Rutaceae }\end{array}$ & $\begin{array}{l}\text { Mamica-de- } \\
\text { porca }\end{array}$ & Me & Folha & AV & 1,00 \\
\hline Lafoensia pacari A.St.-Hil.- Lythraceae & $\begin{array}{c}\text { Mangava- } \\
\text { brava }\end{array}$ & Me & $\begin{array}{l}\text { Casca } \\
\text { Folha }\end{array}$ & AV & 1,00 \\
\hline $\begin{array}{l}\text { Dilodendron bipinnatum Radlk.- } \\
\text { Sapindaceae }\end{array}$ & Maria-pobre & Me & Folha & AV & 1,00 \\
\hline $\begin{array}{l}\text { Alibertia edulis (Rich.) A.Rich.- } \\
\text { Rubiaceae }\end{array}$ & $\begin{array}{l}\text { Marmelada- } \\
\text { bola }\end{array}$ & Me & $\begin{array}{l}\text { Folha } \\
\text { Fruto }\end{array}$ & $\mathrm{AV}$ & 1,00 \\
\hline $\begin{array}{l}\text { Buchenavia tomentosa Eichler- } \\
\text { Combretaceae }\end{array}$ & Mirindiba & Me & Folha & AV & 1,00 \\
\hline $\begin{array}{l}\text { Byrsonima verbascifolia (L.) DC. } \\
\text { Malpighiaceae }\end{array}$ & Murici & $\mathrm{Me}$ & $\begin{array}{l}\text { Folha } \\
\text { Fruto }\end{array}$ & $A B$ & 1,00 \\
\hline $\begin{array}{l}\text { Byrsonima cydoniifolia A.Juss. } \\
\text { Malpighiaceae }\end{array}$ & Muricizinho & Me & Folha & $A B$ & 1,00 \\
\hline $\begin{array}{l}\text { Siparuna guianensis Aubl. } \\
\text { Siparunaceae }\end{array}$ & Negramina & Me & Folha & AV & 1,00 \\
\hline Pereskia aculeata Mill.- Cactaceae & Ora-pro-nobis & Me & Folha & $\mathrm{TR}$ & 1,00 \\
\hline Solanum cernuum Vell. Solanaceae & Panaceia & $\mathrm{Me}$ & Folha & $A B$ & 1,00 \\
\hline $\begin{array}{l}\text { Vochysia rufa Mart. } \\
\text { Vochysiaceae }\end{array}$ & Pau-doce & Me & Casca & $\mathrm{AV}$ & 1,00 \\
\hline $\begin{array}{l}\text { Qualea multiflora Mart. } \\
\text { Vochysiaceae }\end{array}$ & $\begin{array}{l}\text { Pau-terra } \\
\text { macho }\end{array}$ & Me & Folha & $\mathrm{AV}$ & 1,00 \\
\hline $\begin{array}{l}\text { Cybistax antisyphilitica (Mart.) Mart. } \\
\text { Bignoniaceae }\end{array}$ & Pé-de-anta & Me & Folha & $\mathrm{AV}$ & 1,00 \\
\hline Bidens gardneri Baker- Asteraceae & Picão branco & Me & Folha & SA. & 1,00 \\
\hline Bidens pilosa L.- Asteraceae & Picão preto & Me & Folha & SA. & 1,00 \\
\hline $\begin{array}{l}\text { Cordia salicifolia } \mathrm{L} . \\
\text { Boraginaceae }\end{array}$ & Porangaba & Me & Folha & $\mathrm{AV}$ & 1,00 \\
\hline Croton salutaris Casar. Euphorbiaceae & Sangra D'água & $\mathrm{Me}$ & Folha & $\mathrm{AV}$ & 1,00 \\
\hline $\begin{array}{l}\text { Astronium fraxinifolium Schott } \\
\text {-Anacardiaceae }\end{array}$ & Gonçaleiro & Me & Folha & AV & 1,00 \\
\hline
\end{tabular}




\begin{tabular}{l|c|c|c|c|c}
\hline \multicolumn{1}{c|}{ Nome científico/família } & $\begin{array}{c}\text { Nome } \\
\text { popular }\end{array}$ & Usos & $\begin{array}{c}\text { Parte } \\
\text { usada }\end{array}$ & Hábito & VUsp \\
\hline $\begin{array}{l}\text { Amburana cearensis (Allemão) A.C. Sm. } \\
\text { Fabaceae }\end{array}$ & Imburana & Me & Folha & AV & 1,00 \\
\hline $\begin{array}{l}\text { Bauhinia brevipes Vogel Fabaceae } \\
\text { Pata-de-vaca } \\
\text { do campo }\end{array}$ & Me & Folha & SA. & 1,00 \\
\hline
\end{tabular}

Legendas: Usos: alimentar (AI), artesanal (Ar), inseticida (In), madeireiro (Ma), medicinal (Me), ornamental (Or), sombreamento (So) e tempero (Te). Hábito: arbóreo (AV), arbustivo (AB), subarbustivo (SA), palmeira (PA), trepadeira (TR). VUsp = valor de uso global de cada espécie.

Fonte: As próprias autoras.

No cálculo do Valor de Uso, o número de usos mencionados para uma espécie estabelece a importância dela para a comunidade, uma vez que demostra o valor de uso da planta estatisticamente. As espécies mais importantes para a comunidade, conforme o valor de uso foram cumbaru, angico e aroeira (Tabela 1). São necessários mais estudos que avaliem o impacto sobre essas espécies, sobretudo a aroeira, uma vez que ela se encontra na "Lista Oficial da Flora Brasileira Ameaçada de Extinção" (BRASIL, 2008).

Poucas espécies alcançaram alto valor de uso, assim como em Chocó - Colômbia (GALEANO, 2000) e em Alagoinha (ALBUQUERQUE; ANDRADE; SILVA, 2005), onde constataram que a maior parte das espécies utilizáveis possuíam baixos valores de uso, enquanto altos valores estavam agrupados em poucas espécies. As espécies mais abundantes ou as mais empregadas para diferentes finalidades não são necessariamente as mais importantes para uma comunidade, demonstrando que as espécies raras, às vezes, possuem mais diversificação de uso que as mais comuns (ALBUQUERQUE; ANDRADE, 2002). Além disso, uma pessoa pode conhecer vários usos para uma única espécie.

\section{CONSIDERAÇÕES FINAIS}

Conhecer as espécies úteis de uma comunidade, assim como a abundância de indivíduos das espécies é primordial para o planejamento de áreas de conservação de uso sustentável. Essas informações podem compor indicativos de espécies potencialmente exploradas e que merecem mais estudos sobre a dinâmica populacional, no intuito de se estabelecer taxas máximas de coleta sustentável e um manejo que permita a manutenção das plantas ao longo do tempo.

A pesquisa foi importante por fornecer dados para estudos futuros sobre o uso terapêutico da flora local, bem como para divulgar a diversidade e a potencialidade do Cerrado da região do Estado de Mato Grosso. Além de mais pesquisas, é indispensável a implementação de projetos a fim de estimular as práticas tradicionais e o uso dos recursos nativos, de modo a conservar o saber local das comunidades e apresentar opções que amorteçam o impacto da coleta sobre as populações naturais.

\section{Agradecimentos}

A todos os moradores da comunidade São Miguel por terem contribuído com a pesquisa e que gentilmente com toda humildade nos receberam. À Coordenação de Aperfeiçoamento de Pessoa de Nível Superior (CAPES), pela bolsa de mestrado concedida à primeira autora. 


\section{REFERÊNCIAS}

ALBUQUerQue, Ulisses Paulino; ANDRADE, Laise de Holanda Cavalcanti. Conhecimento botânico tradicional e conservação em uma área de caatinga no estado de Pernambuco, Nordeste do Brasil. Acta Botanica Brasilica, São Paulo, v. 16, n. 3, p. 273-85, 2002.

Albuquerque, Ulisses Paulino; LUCENA, Reinaldo Farias Paiva de; ALENCAR, Nelson Leal. Métodos e técnicas na coleta de dados etnobiológicos. In: ALBUQUERQUE, Ulisses Paulino (Org.). Métodos e técnicas na pesquisa etnobiológica e etnoecológica. São Paulo: NUPEEA, 2010. p. 65-82.

ALBUQUerQUe, Ulisses Paulino; ANDRADE, Laise de Holanda Cavalcanti; SILVA, Ana Carolina Oliveira de. Use of plant resources in a seasonal dry forest (Northeastern Brazil). Acta Botanica Brasilica, São Paulo, v. 19, n. 1, p. 27-38, 2005.

AMOROZO, Maria Christina de Mello. Uso e diversidade de plantas medicinais em Santo Antônio do Leverger, MT, Brasil. Acta Botanica Brasilica, São Paulo, v. 16, n. 2, p. 189-203, 2002.

BEZERRA, Gabrieli da Penha. Estudos farmoquímicos bioguiado pela atividade miorrelaxante do extrato etanólico das cascas do caule de Hymenaea courbaril L. (Jatobá). 2013. 129f. Dissertação (Mestrado em Farmacêuticas)- Universidade Federal do Ceará, Fortaleza, 2013.

BRASIL. Ministério do Meio Ambiente (MMA). O bioma Cerrado. [s.d.]. Disponível em: http://www.mma. gov.br/biomas/Cerrado. Acesso em: 3 nov. 2014.

BRASIL. Ministério do Meio Ambiente (MMA). Instrução Normativa n. 6, de 23 de setembro de 2008. Disponível em: https://www.mma.gov.br/estruturas/179/_arquivos/179_05122008033615.pdf. Acesso em: 19 nov. 2014.

BRASIL. Ministério das Minas e Energia. Secretária-geral. Projeto RADAMBRASIL (Levantamento de Recursos Naturais, 21). Folha SD-21, Cuiabá. Rio de Janeiro, 1982. p. 1-540.

CABALLERO, Javier. La etnobotânica. In: BARRER, A. (Ed.). La etnobotânica: tres puntos de vista y uma perspectiva. Xalapa, México: Instituto de Investigación sobre Recursos Bióticos, 1979. p. 27-30.

CARNIELLO, Maria Antonia; SILVA, Roberta dos Santos; CRUZ, Maria Aparecida Berbem da; GUARIM NETO, Germano. Quintais urbanos de Mirassol D'Oeste-MT, Brasil: uma abordagem etnobotânica. Acta Amazônica, Manaus, v. 40, n. 3, p. 451-70, 2010.

CUNHA, Simone Alves da; BORTOLOTTO, leda Maria. Etnobotânica de plantas medicinais no Assentamento Monjolinho, município de Anastácio, Mato Grosso do Sul, Brasil. Acta Botanica Brasilica, São Paulo, v. 25, n. 3, p. 685-98, jul./set. 2011.

DAHER, Felipe Rodrigues Gil; DORVAL, Alberto; COSTA, Reginaldo Brito da; PASA, Maria Corette. Aspectos etnobiológicos na comunidade Coivaras, Chapada dos Guimarães, MT, Brasil. Revista de Ciências AgroAmbientais, Alta Floresta, MT, v. 10, n. 2, p. 149, 2012.

EMPRESA BRASILEIRA DE PESQUISA AGROPECUÁRIA (EMBRAPA). Vegetação. [s.d.]. Disponível em: http:// cmbbc.cpac.embrapa.br/vegetacao.htm. Acesso em: 6 nov. 2014.

GALEANO, Gloria. Forest use at the Pacific Coast of Chocó, Colômbia: a quantitative approach. Economic Botany, v. 54, n. 3, p. 358-76, 2000.

GUARIM-NETO, Germano. Flora medicinal, populações humanas e o ambiente de cerrado. Horticultura Brasileira, Brasília v.19, p. 203-6, 2001. 
KLINK, Carlos A.; MACHADO, Ricardo B. A conservação do Cerrado brasileiro. Megadiversidade, v. 1, n. 1, p. 147-55, 2005.

MAMEDE, Jeneffer Soares dos Santos; DE DAVID, Margo; TSUKAMOTO FILHO, Antônio de Arruda; PASA, Maria Corette. Os quintais e as manifestações culturais da comunidade São Gonçalo Beira Rio, Cuiabá, MT. Revista Biodiversidade, Rondonópolis, MT, v. 14, n. 1, p. 168-82, 2015.

MENDONÇA, Marcelo Rodrigues; PELÁ, Márcia. O Cerrado goiano numa encruzilhada de tempos: os territórios em disputa e as novas territorialidades do conflito. Revista Geográfica de América Central, Costa Rica, v. 2, n. 47, p. 1-18, 2011.

MONTEIRO, Júlio Marcelino et al. Teor de taninos em três espécies medicinais arbóreas simpátricas da caatinga. Revista Árvore, Viçosa, MG, v. 29, n. 6, p. 999-1005, nov./dez. 2005.

MOREIRA, Déborah Luíza; GUARIM-NETO, Germano. Usos múltiplos de plantas do Cerrado: um estudo etnobotânico na comunidade sitio Pindura, Rosário Oeste, Mato Grosso, Brasil. Polibotánica, México, n. 27, p. 159-90, 2009.

PAES, Nayara Dores da Silva; PASA, Maria Corette. Vegetação, cultura e economia: aspectos etnobotânicos da comunidade Capão em Barão de Melgaço, Mato Grosso, Brasil. FLOVET - Boletim do Grupo de Pesquisa da Flora, Vegetação e Etnobotânica, Cuiabá, v. 1, n. 6, p. 65-84, 2014.

PASA, Maria Corette. Saber local e medicina popular: a etnobotânica em Cuiabá, Mato Grosso, Brasil. Boletim do Museu Paraense Emílio Goeldi. Ciências Humanas, Belém, PA, v. 6, n. 1, p. 179-96, 2011a.

PASA, Maria Corette. Abordagem etnobotânica na Comunidade de Conceição Açu, Mato Grosso, Brasil. Polibotánica, México, n. 31, p. 169-97, 2011b.

PASA, Maria Corette; SOARES João Juares; GUARIM-NETO, Germano. Estudo etnobotânico na comunidade de Conceição-Açu (alto da bacia do rio Aricá Açu, MT, Brasil). Acta Botanica Brasilica, São Paulo, v. 19, n. 2, p. 195-207, abr./jun. 2005.

PASA, Maria Corette et al. Abordagem qualiquantitativa em etnobotânica. In: PASA, Maria Corette (Org.). Múltiplos olhares sobre a biodiversidade. Jundiaí, SP: Paco Editorial, 2013. p. 215-24.

PHILLIPS, Oliver; GENTRY, Alwyn H. The useful plants of Tambopata, Peru: I. Statistical hypotheses tests with a new quantitative technique. Economic Botany, v. 47, n. 1, p. 15-32, 1993.

QUEIROZ, Carla Regina Amorim dos Anjos; MORAIS, Sérgio Antônio Lemos de. NASCIMENTO, Evandro Afonso do. Caracterização dos taninos da aroeira-preta (Myracrodruon urundeuva). Revista Árvore, Viçosa, MG, v. 26, n. 4, p. 485-92, jul./ago. 2002.

ROMANCINI, Sônia Regina; MOURA, Edenilson Dutra de. Um olhar para a Passagem da Conceição em Várzea Grande (MT). Revista do Instituto Histórico e Geográfico de Mato Grosso, Cuiabá, n. 70, 259 p., 2012.

SÓLON, Soraya; BRANDÃO, Luiz Fabrício Gardini; SIQUEIRA, João Máximo. O gênero Cochlospermum Kunth com ênfase nos aspectos etnobotânicos, farmacológicos, toxicológicos e químicos de Cochlospermum regium (Mart. Et. Schr.) Pilger. Revista Eletrônica de Farmácia, Goiás, v. 6, n. 3, p. 1-22, 2009.

SOUZA, Luzia Francisca. Recursos vegetais usados na medicina tradicional do Cerrado (comunidade de Baús, Acorizal, MT, Brasil). Revista Brasileira de Plantas Medicinais, Botucatu, SP, v. 9, n. 4, p. 44-54, 2007.

VALENTINI, Carla Maria Abido; ALMEIDA, Juliane Dias de; COELHO, Maria de Fátima Barbosa; ORTíZ, 
Carmen Eugenia Rodríguez. Uso de Siparuna guianensis Aublet (negramina) em Bom Sucesso, município de Várzea Grande, Mato Grosso. Revista de Biologia Neotropical, Goiânia, v. 5, n.2, p. 11-22, 2008.

VERTRAG. Prefeitura Municipal de Várzea Grande. Plano Diretor Participativo do Município de Várzea Grande: 2007-2017. 2007. Disponível em: https://sogi8.sogi.com.br/Arquivo/Modulo113.MRID109/ Registro13079/documento\%201\%20-\%20antreprojeto\%20plano\%20diretor\%20-\%20lei\%203112-2007. pdf. Acesso em: 23 out. 2019.

ZSCHOCKE, Sibylle; RABE, Tonia; TAYLOR, Joslyn L. S.; JÄGER, Anna K.; VAN STADEN, Johannes M. Planta part substitution - a way to conserve edangered medicinal plantas? Journal of Ethnopharmacology, $\mathrm{v}$. 71, n. 1-2, p. 281-92, jul. 2000.

ZUCCHI, Marcelo Ribeiro et al. Levantamento etnobotânico de plantas medicinais na cidade de Ipameri - GO. Revista Brasileira Plantas Medicinais, Botucatu, SP, v. 15, n. 2, 2013.

\section{Sobre as autoras:}

Jenefer Soares dos Santos Mamede: Mestre Ciências Florestais e Ambientais na Universidade Federal de Mato Grosso (UFMT). Especialista em Engenharia e Segurança do Trabalho pela Universidade de Cuiabá (UNIC). Graduada em Engenheira Florestal pela Universidade do Estado de Mato Grosso (UNEMAT). Trabalha com licenciamentos ambientais em áreas rurais. E-mail: jenefferss@gmail.com, Orcid: http://orcid.org/0000-0003-1720-2402

Maria Corette Pasa: Pós-Doutora em Etnobotânica e Etnofarmacobotânica na Cultura de Comunidades Afrodescendentes - Brasil / Europa / África. Doutora em Ciências - Ecologia e Recursos Naturais pela Universidade Federal de São Carlos (UFSCar), SP. Mestre em Ecologia e Conservação da Biodiversidade pela Universidade Federal de Mato Grosso (UFMT). Professora da Classe Associado do Departamento de Botânica e Ecologia - Instituto de Biociências UFMT. Consultora ad hoc de periódicos nacionais e internacionais. Editora-chefe dos Periódicos BIODIVERSIDADE e FLOVET- Flora, Vegetação e Etnobotânica- UFMT. Líder do Grupo de Pesquisa ESCER - Estudando o Cerrado - CNPq/CAPES. Membro de DGPs com certificação nacional e internacional IVR (Inteligência Vibracional Reversa) pela Universidade Federal de Santa Catarina (UFSC). E-mail: pasamc@brturbo.com.br, Orcid: http://orcid.org/0000-0001-5304-5294 